\title{
SPECTRAL METHOD FOR 3-DIMENSIONAL POISSON'S EQUATION IN CYLINDRICAL COORDINATES WITH REGULAR BOUNDARIES*
}

\author{
Yuri K. Batygin \\ Stanford Linear Accelerator Center, Stanford University, Stanford, CA 94309, USA
}

\section{Abstract}

Method of calculation of space charge field of the beam using an expansion of space charge potential and space charge distribution as Fourier-Bessel series is discussed. Coefficients of series are connected by an algebraic equation, which substantially simplifies solution of the problem. Efficiency and accuracy of the method are discussed. Suggested method is effective in multidimensional problems of study of intense chargedparticle beams.

\section{INTRODUCTION}

Accurate calculation of space charge potential of the beam is important for precise simulation of high current beam dynamics in particle accelerators. The most popular approaches combine finite difference methods and Fast Fourier Transforms where Poisson's equation is substituted by a finite-difference equation and resulted matrix equation is solved to find the grid function of potential [1]. In spectral methods solution of the problem is expressed as analytical functions [2], [3]. It provides more exact solution and simplifies numerical algorithm. Numerical solution in this case is a Fourier spectrum, which can be easily verified. However, spectral methods are usually slow.

\section{MATHEMATICAL ALGORITHM}

Consider periodic distribution of a space charge density of the beam in perfect conducting pipe of radius a (see Fig. 1). Space charge potential of the beam is calculated via solution of the Poisson's equation:

$$
\frac{1}{\mathrm{r}} \frac{\partial}{\partial \mathrm{r}}\left(\mathrm{r} \frac{\partial \Phi}{\partial \mathrm{r}}\right)+\frac{1}{\mathrm{r}^{2}} \frac{\partial^{2} \Phi}{\partial \varphi^{2}}+\frac{\partial^{2} \Phi}{\partial \mathrm{z}^{2}}=-\frac{\rho(\mathrm{r}, \varphi, \mathrm{z})}{\varepsilon_{\mathrm{o}}},
$$

with Dirichlet boundary conditions for potential $\Phi$ at the surface of conducting pipe and periodic conditions in longitudinal direction $\mathrm{z}$ :

$$
\begin{aligned}
& \Phi(\mathrm{a}, \varphi, \mathrm{z})=0, \\
& \Phi(\mathrm{r}, \varphi, \mathrm{z})=\Phi(\mathrm{r}, \varphi, \mathrm{z}+\mathrm{L})
\end{aligned}
$$

Let us express unknown potential $\Phi(\mathrm{r}, \varphi, \mathrm{z})$ and space charge distribution $\rho(r, \varphi, z)$ as Fourier-Bessel series:

\footnotetext{
*Work supported by the Department of Energy contract DEAC03-76SF00515
}

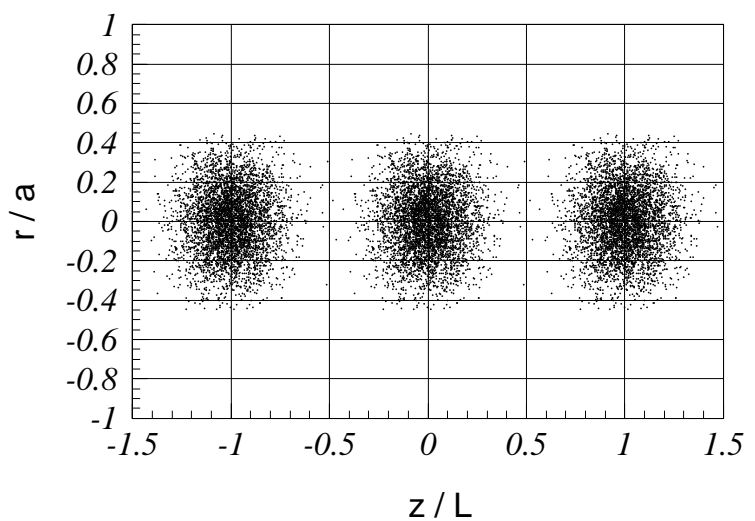

Fig. 1. Periodic distribution of charged particles.

$$
\begin{aligned}
& \Phi=\sum_{\mathrm{k}=-\mathrm{K}}^{\mathrm{K}} \sum_{\mathrm{n}=-\mathrm{N}}^{\mathrm{N}} \sum_{\mathrm{m}=1}^{\mathrm{M}} \bar{\Phi}_{\mathrm{kmn}} \mathrm{J}_{\mathrm{n}}\left(\mathrm{v}_{\mathrm{nm}} \frac{\mathrm{r}}{\mathrm{a}}\right) \mathrm{e}^{-\mathrm{i}\left(\frac{2 \pi \mathrm{kz}}{\mathrm{L}}+\mathrm{n} \varphi\right),} \\
& \rho=\sum_{\mathrm{k}=-\mathrm{K}}^{\mathrm{K}} \sum_{\mathrm{n}=-\mathrm{N}}^{\mathrm{N}} \sum_{\mathrm{m}=1}^{\mathrm{M}} \bar{\rho}_{\mathrm{kmn}} \mathrm{J}_{\mathrm{n}}\left(\mathrm{v}_{\mathrm{nm}} \frac{\mathrm{r}}{\mathrm{a}}\right) \mathrm{e}^{-\mathrm{i}\left(\frac{2 \pi \mathrm{kz}}{\mathrm{L}}+\mathrm{n} \varphi\right),}
\end{aligned}
$$

where $J_{n}(x)$ is the Bessel function of the order $n ; v_{n m}$ is the $\mathrm{m}$-th root of the equation $\mathrm{J}_{\mathrm{n}}(\mathrm{x})=0$. Coefficients of space charge potential expansion in Eq. (5) are obtained from inverse Fourier-Bessel transformation:

$\bar{\rho}_{\mathrm{kmn}}=\frac{\int_{\mathrm{o}}^{\mathrm{a}} \int_{\mathrm{o}}^{\mathrm{L}} \int_{0}^{2 \pi} \rho(\mathrm{r}, \varphi, \mathrm{z}) \mathrm{J}_{\mathrm{n}}\left(\nu_{\mathrm{nm}} \frac{\mathrm{r}}{\mathrm{a}}\right) \mathrm{e}^{\mathrm{i}\left(\frac{2 \pi \mathrm{kz}}{\mathrm{L}}+\mathrm{n} \varphi\right)} \mathrm{rdr} \boldsymbol{d} \varphi \mathrm{dz}}{\pi \mathrm{a}^{2} \mathrm{~L} \mathrm{~J}_{\mathrm{n}+1}^{2}\left(\nu_{\mathrm{nm}}\right)}$.

Eq. (6) is obtained using orthogonality of Bessel functions

$$
\int_{0}^{1} J_{m}\left(\mu_{i} x\right) J_{m}\left(\mu_{k} x\right) x d x=\left\{\begin{array}{ll}
0, & i \neq k \\
\frac{1}{2}\left[J_{m+1}\left(\mu_{i}\right)\right]^{2}, & i=k
\end{array} .\right.
$$

After substitution of the expansions (4), (5) into Poisson's equation (1), the coefficients of potential, $\bar{\Phi}_{\mathrm{kmn}}$, and space charge distribution, $\bar{\rho}_{\mathrm{kmn}}$, are connected by the algebraic equation: 


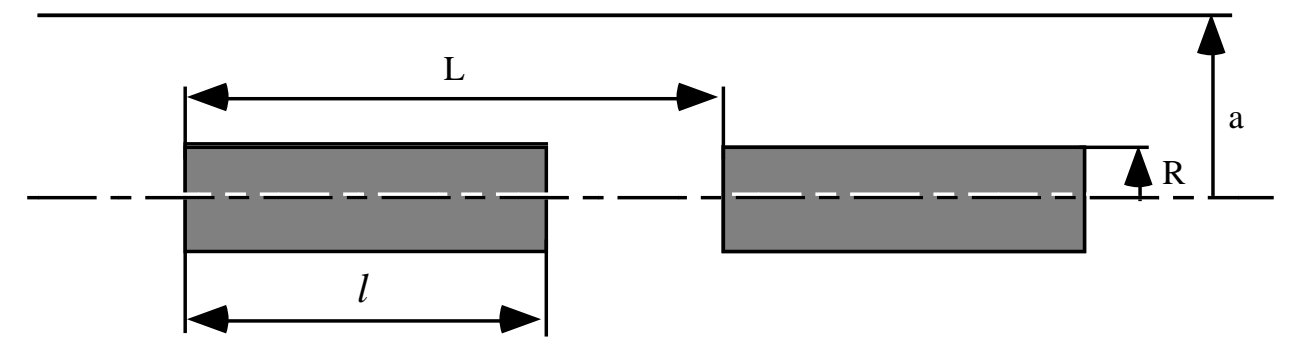

Fig. 2. Periodic train of uniformly charged cylindrical bunches.

$$
\bar{\Phi}_{\mathrm{kmn}}=\frac{\bar{\rho}_{\mathrm{kmn}}}{\varepsilon_{\mathrm{o}}\left[\left(\frac{2 \pi \mathrm{k}}{\mathrm{L}}\right)^{2}+\left(\frac{v_{\mathrm{nm}}}{\mathrm{a}}\right)^{2}\right]} .
$$

Algorithm of space charge potential calculation is performed as 3 steps:

- calculation of coefficients of space charge distribution, Eq. (6),

- calculation of coefficients of space charge potential, Eq.

(8),

- calculation of space charge potential, Eq. (4).

In special cases the problem can be simplified. For example, if the region is limited in longitudinal direction by conductive surfaces, it is enough to use expression:

$\Phi=\sum_{\mathrm{k}=1}^{\mathrm{K}} \sum_{\mathrm{n}=-\mathrm{N}}^{\mathrm{N}} \sum_{\mathrm{m}=1}^{\mathrm{M}} \bar{\Phi}_{\mathrm{kmn}} \mathrm{J}_{\mathrm{n}}\left(\mathrm{v}_{\mathrm{nm}} \frac{\mathrm{r}}{\mathrm{a}}\right) \mathrm{e}^{-\mathrm{in} \varphi} \sin \left(\frac{\pi \mathrm{kz}}{\mathrm{L}}\right)$

analogously for $\rho(\mathrm{r}, \varphi, \mathrm{z})$.

\section{CONVERGENCE OF ALGORITHM}

To estimate convergence of the series (4), (5), let us calculate potential of the periodic sequence of uniformly charged bunches of radius $\mathrm{R}<\mathrm{a}$, length $l<\mathrm{L}$ and charge density $\rho_{\mathrm{o}}$ (see Fig. 2). For that problem the coefficients, Eq. (6), are calculated analytically:

$$
\rho_{\mathrm{kmo}}=\rho_{\mathrm{o}} \frac{4}{v_{\mathrm{om}}}\left(\frac{\mathrm{R}}{\mathrm{a}}\right)\left(\frac{l}{\mathrm{~L}}\right)\left[\frac{\mathrm{J}_{1}\left(v_{\mathrm{om}} \frac{\mathrm{R}}{\mathrm{a}}\right)}{\mathrm{J}_{1}^{2}\left(v_{\mathrm{om}}\right)}\right]\left[\frac{\sin \left(\frac{\pi \mathrm{k} l}{\mathrm{~L}}\right)}{\left(\frac{\pi \mathrm{k} l}{\mathrm{~L}}\right)}\right] .
$$

Analysis shows that the values of $\rho_{\mathrm{kmo}}$ decrease as $\sim 1 /(\sqrt{\mathrm{m}} \mathrm{k})$. Substitution of Eq.(10) into Eqs. (8), (4) gives expression for potential of the train of cylindrical bunches:

$$
\Phi(\mathrm{r}, \mathrm{z})=\sum_{\mathrm{k}=1}^{\infty} \sum_{\mathrm{m}=1}^{\infty} \frac{4 \rho_{\mathrm{o}}}{\varepsilon_{\mathrm{o}} v_{\mathrm{om}}\left[\left(\frac{2 \pi \mathrm{k}}{\mathrm{L}}\right)^{2}+\left(\frac{v_{\mathrm{om}}}{\mathrm{a}}\right)^{2}\right]} .
$$

$$
\left(\frac{\mathrm{R}}{\mathrm{a}}\right)\left(\frac{l}{\mathrm{~L}}\right) \frac{\mathrm{J}_{1}\left(v_{\mathrm{om}} \frac{\mathrm{R}}{\mathrm{a}}\right)}{\mathrm{J}_{1}^{2}\left(v_{\mathrm{om}}\right)} \frac{\sin \left(\frac{\pi \mathrm{k} l}{\mathrm{~L}}\right)}{\left(\frac{\pi \mathrm{k} l}{\mathrm{~L}}\right)} \mathrm{J}_{\mathrm{O}}\left(v_{\mathrm{om}} \frac{\mathrm{r}}{\mathrm{a}}\right) \cos \left(\frac{2 \pi \mathrm{kz}}{\mathrm{L}}\right) .
$$

Coefficients $\bar{\Phi}_{\mathrm{kmo}}$ decrease in this case as

$$
\bar{\Phi}_{\mathrm{kmo}} \sim \frac{1}{\mathrm{mk}\left(\mathrm{m}^{2}+\mathrm{k}^{2}\right)} .
$$

Example shows that the expression for potential is fast convergent. Realistic beam usually has a smooth distribution of space charge density. It is expected, that in practice the small number of coefficients in series, Eqs. (4), (5) is enough to obtain the required accuracy.

\section{NUMERICAL EXAMPLE}

Suggested algorithm was tested for the problem of space charge potential of the axial - symmetric beam. Calculations were done for test function

$$
\Phi(\mathrm{r}, \mathrm{z})=\left[1-\left(\frac{\mathrm{r}}{\mathrm{a}}\right)^{4}\right]\left(\cos \frac{\pi \mathrm{z}}{\mathrm{L}}\right)^{4},
$$

which satisfies the boundary conditions, Eqs. (2), (3). The corresponding value of space charge is given by:

$$
\begin{aligned}
\frac{\rho(\mathrm{r}, \mathrm{z})}{\varepsilon_{\mathrm{o}}}= & 16 \frac{\mathrm{r}^{2}}{\mathrm{a}^{4}}\left(\cos \frac{\pi \mathrm{z}}{\mathrm{L}}\right)^{4}+ \\
& \left(\frac{2 \pi}{\mathrm{L}}\right)^{2}\left[1-\left(\frac{\mathrm{r}}{\mathrm{a}}\right)^{4}\right]\left[\left(\cos \frac{\pi \mathrm{z}}{\mathrm{L}}\right)^{4}-\frac{3}{4}\left(\cos \frac{2 \pi \mathrm{z}}{\mathrm{L}}\right)^{2}\right] .
\end{aligned}
$$

Cylindrical region $0<\mathrm{r}<\mathrm{a}, 0<\mathrm{z}<\mathrm{L}$, was covered by the grid with steps $\mathrm{h}_{\mathrm{r}}=\mathrm{a} / \mathrm{N}_{\mathrm{r}}, \mathrm{h}_{\mathrm{Z}}=\mathrm{L} / \mathrm{N}_{\mathrm{Z}}$, where $\mathrm{N}_{\mathrm{r}}, \mathrm{N}_{\mathrm{Z}}$ are 
the number of grid points in $\mathrm{r}$ and $\mathrm{z}$, respectively. Coefficients in space charge density expansion, Eq. (5), are expressed as :

$$
\begin{aligned}
\bar{\rho}_{\mathrm{kmo}}= & \frac{2}{\mathrm{~J}_{1}^{2}\left(\mathrm{v}_{\mathrm{om}}\right) \mathrm{N}_{\mathrm{r}} \mathrm{N}_{\mathrm{Z}}} . \\
& \sum_{\mathrm{s}=0}^{\mathrm{N}_{\mathrm{Z}}-1} \sum_{\mathrm{j}=1}^{\mathrm{N}_{\mathrm{r}}-1} \rho_{\mathrm{sj}}\left(\frac{\mathrm{r}_{\mathrm{j}}}{\mathrm{a}}\right) \mathrm{J}_{\mathrm{O}}\left(v_{\mathrm{mo}} \frac{\mathrm{r}_{\mathrm{j}}}{\mathrm{a}}\right) \exp \left(\mathrm{i} \frac{\left.2 \pi \mathrm{k}_{\mathrm{z}_{\mathrm{s}}}\right),}{\mathrm{L}}\right.
\end{aligned}
$$

where the grid points are used:

$$
\begin{array}{lll}
z_{\mathrm{S}}=\mathrm{s} \cdot \mathrm{h}_{\mathrm{z}}, & \mathrm{s}=0,1,2, \ldots \ldots & \mathrm{N}_{\mathrm{z}}-1, \\
\mathrm{r}_{\mathrm{j}}=\mathrm{j} \cdot \mathrm{h}_{\mathrm{r}}, & \mathrm{j}=0,1,2, \ldots \ldots & \mathrm{N}_{\mathrm{r}}-1 .
\end{array}
$$

For z-expansion the Fast Fourier Transform was used. The number of coefficients in $\mathrm{z}$-direction was equal to the number of grid points, $\mathrm{K}=\mathrm{N}_{\mathrm{Z}}$. The number of coefficients in radial direction $\mathrm{M}$ was varied. An averaged deviation of numerical solution, $\Phi\left(\mathrm{r}_{\mathrm{j}}, \mathrm{z}_{\mathrm{S}}\right)$, from the exact analytical solution, $\Phi(\mathrm{r}, \mathrm{z})$, was calculated as an error $\delta$ :

$$
\delta=\frac{1}{N_{Z} N_{r}} \sqrt{\sum_{s=0}^{N_{Z^{-}}} \sum_{j=1}^{N_{r}-1}\left[\Phi(r, z)-\Phi\left(r_{j}, z_{S}\right)\right]^{2}} .
$$

Results of calculation are summarized in Table 1.

For comparison, the same problem was tested by the finite-difference method. Poisson's equation (1) was substituted by the finite-difference analog:

$$
\begin{aligned}
& U_{k, j+1}\left(1+\frac{1}{2(j-1)}\right)-2 U_{k, j}\left(1+\frac{h_{r}^{2}}{h_{z}^{2}}\right)+U_{k, j-1}\left(1-\frac{1}{2(j-1)}\right) \\
& +U_{k+1, j}\left(\frac{h_{r}}{h_{z}}\right)^{2}+U_{k-1, j}\left(\frac{h_{r}}{h_{z}}\right)^{2}=-\frac{\rho_{k, j}}{\varepsilon_{o}} h_{r}^{2} .
\end{aligned}
$$

Calculations started with Fourier expansion of unknown potential, $\mathrm{U}_{\mathrm{k}, \mathrm{j}}$, in $\mathrm{z}$-direction

$$
\mathrm{U}_{\mathrm{k}, \mathrm{j}}=\sum_{\mathrm{m}=1}^{\mathrm{N}_{\mathrm{z}}} \overline{\mathrm{U}}_{\mathrm{m}}(\mathrm{j}) \exp \left(-\mathrm{i} \frac{2 \pi(\mathrm{k}-1)(\mathrm{m}-1)}{\mathrm{N}_{\mathrm{Z}}}\right) \text {, }
$$

Table 1. Error $\delta$ of the test problem.

Spectral method

Grid
Finite -difference

$$
\mathrm{M}=5 \quad \mathrm{M}=10 \quad \mathrm{M}=40 \quad \text { method }
$$

$\begin{array}{lcccc}16 \times 16 & 3 \cdot 10^{-4} & 3 \cdot 10^{-4} & 3 \cdot 10^{-4} & 3 \cdot 10^{-4} \\ 32 \times 32 & 1 \cdot 10^{-4} & 4 \cdot 10^{-5} & 3 \cdot 10^{-5} & 4 \cdot 10^{-5} \\ 64 \times 64 & 6 \cdot 10^{-5} & 1 \cdot 10^{-5} & 4 \cdot 10^{-6} & 6 \cdot 10^{-6} \\ 128 \times 128 & 3 \cdot 10^{-5} & 5 \cdot 10^{-6} & 5 \cdot 10^{-7} & 1 \cdot 10^{-6} \\ 256 \times 256 & 1 \cdot 10^{-5} & 2 \cdot 10^{-6} & 1 \cdot 10^{-7} & 1 \cdot 10^{-6}\end{array}$

similar for space charge density $\rho_{\mathrm{k}, \mathrm{j}}$. Coefficients of Fourier expansion, $\overline{\mathrm{U}}_{\mathrm{m}}(\mathrm{j})$, were expressed via inverse Fourier transform:

$$
\overline{\mathrm{U}}_{\mathrm{m}}(\mathrm{j})=\frac{1}{\mathrm{~N}_{\mathrm{Z}}} \sum_{\mathrm{k}=1}^{\mathrm{N}_{\mathrm{Z}}} \mathrm{U}_{\mathrm{kj}} \exp \left(\mathrm{i} \frac{2 \pi(\mathrm{k}-1)(\mathrm{m}-1)}{\mathrm{N}_{\mathrm{Z}}}\right)
$$

and similar for $\bar{\rho}_{m}(j)$. Substitution of expansion, Eq. (21), into the finite-difference analog of the Poisson's equation, Eq. (19), results in a three-diagonal matrix equation:

$$
\alpha_{j} \bar{U}_{m}(j+1)+\beta_{j} \bar{U}_{m}(j)+\gamma_{j} \bar{U}_{m}(j-1)=w_{j},
$$

which was solved utilizing the Gauss elimination method [1]. After that, the potential in grid points was calculated using Fourier series, Eq. (20).

Comparison of numerical results shows that spectral method gives better accuracy than the finite-difference one using relatively small number of harmonics $\mathrm{M}$ in radial direction.

\section{REFERENCES}

[1] D.Potter, Computational Physics, J.Wiley, London, 1973.

[2] A.S.Roshal, Simulation of Charged Particles, Moscow, Atomizdat, 1979 (in Russian).

[3] R.W.Hockney and J.W.Eastwood, Computer Simulation Using Particles, McGraw-Hill, New York, 1981. 